\title{
Effects of single-session dietary counseling by dieticians on salt reduction in cardiology outpatients who consumed large amounts of salt
}

\author{
TAMAMI YAMASAKI $^{1}$, TSUNEAKI SADANAGA ${ }^{2-4}$ and SHINICHI HIROTA ${ }^{2}$ \\ ${ }^{1}$ Office of Nutrition, Ueki Hospital, Kumamoto 861-5347; ${ }^{2}$ Division of Cardiology, Ueki Hospital, Kumamoto 861-5347; \\ ${ }^{3}$ Division of Cardiology, Seigato Hospital, Kumamoto 861-5347; ${ }^{4}$ Department of Cardiology, \\ Keio University School of Medicine, Tokyo 108-8345, Japan
}

Received August 2, 2014; Accepted April 13, 2015

DOI: $10.3892 / \mathrm{etm} .2015 .2452$

\begin{abstract}
The purpose of the present study was to assess the effects of single-session dietary counseling on salt restriction in Japanese cardiology outpatients as assessed using spot urine measurements. A total of 72 patients $(73 \pm 11$ years old, including 30 females) who visited a cardiology outpatient clinic and had a salt intake of $>8 \mathrm{~g} /$ day were included in this study. The patients received dietary counseling for salt restriction by expert dieticians at the time of enrollment. The daily dietary salt intake was estimated using the spot urine test at baseline prior to dietary counseling, at 3-9 weeks (next office visit), and at 24-52 weeks during follow-up evaluations. The baseline level of estimated salt excretion was $11.3 \pm 1.5 \mathrm{~g} / \mathrm{day}$, which was reduced to $9.6 \pm 2.3 \mathrm{~g} /$ day $(\mathrm{P}<0.01)$ at $3-9$ weeks, but increased again at 24-52 weeks to $10.4 \pm 2.1 \mathrm{~g} /$ day, which was less than the baseline value ( $\mathrm{P}=0.034$ vs. $3-9$ weeks; $\mathrm{P}=0.025$ vs. baseline). The numbers of patients who achieved salt excretion levels of $<6.0$ and $<8.0 \mathrm{~g}$ /day at 3-9 weeks were $4(5.6 \%)$ and $19(26 \%)$ patients, respectively, and were further reduced to no patients $(0 \% ; \mathrm{P}=0.043$ vs. $3-9$ weeks $)$ and $9(13 \%$; $\mathrm{P}=0.035$ vs. 3-9 weeks) patients at 24-52 weeks of follow-up evaluation, respectively. In conclusion, the efficacy of dietary counseling by expert dieticians in restricting the salt intake of patients who consumed large amounts of salt was modest and temporary. Multiple nutritional- and behavioral-oriented approaches should be considered to achieve further reductions in salt intake.
\end{abstract}

Correspondence to: Dr Tsuneaki Sadanaga, Division of Cardiology, Seigato Hospital, Funatsu 897, Kumamoto 861-5347, Japan

E-mail: kamefu@rb3.so-net.ne.jp

Key words: salt, dietary counseling, spot urine

\section{Introduction}

Dietary salt restriction is recommended for the prevention of cardiovascular disease in patients with hypertension and heart failure as well as in the general population $(1,2)$. However, salt reduction is challenging to achieve in the real world, particularly in countries in which salt consumption is extremely high, such as Japan. We have previously reported that the estimation of salt intake using the spot urine method may be a useful tool to motivate patients to reduce their salt intake for 8-26 weeks (3), and the efficacy of this method was found to be maintained at long-term (up to 2 years) follow-up (4). However, the percentage of patients who could achieve a reduction in salt intake to the recommended level was very low $(<10-15 \%)(3,4)$. In particular, patients who habitually consume large amounts of salt at baseline find it difficult to reduce salt intake to the recommended level regardless of gender, age and body weight (4). This might be partly explained by the lack of dietary counseling by expert dietitians in the majority (93\%) of the patients included in the previous study (4).

The purpose of the present study was to assess the effects of single-session dietary counseling on salt reduction in addition to the spot urine-guided salt reduction approach in outpatients who consumed large amounts of salt.

\section{Materials and methods}

Patients. This was a prospective observational study of patients who visited the outpatient cardiology clinic of Ueki Hospital (Kumamoto, Japan) between May 2011 and October 2013. These patients were followed up until April 2014. Salt excretion was measured at the time of enrollment, the next office visit (3-9 weeks) and at 24-52 weeks during follow-up. The average level of salt excretion during the 24 weeks prior to the time of enrollment was used as the baseline value. The average level of salt excretion during weeks 24-52 was used as the week 24-52 value. Salt excretion at the time of the next office visit at 3-9 weeks was not averaged (single value). Attending physicians explained the individual data to the patients and encouraged them to reduce their salt intake by 
simple counseling at every office visit when their salt excretion was measured. Dietary counseling by expert dietitians was provided to the patients at the discretion of the attending physicians. Patients who had a salt intake of $>8.0 \mathrm{~g} / \mathrm{day}$ as estimated using the spot urine method at baseline and received dietary counseling by expert dieticians were included in this study. Age- and gender-matched patients who did not received dietary counseling by dieticians and consumed $>8 \mathrm{~g} /$ day of salt served as control patients. They were retrospectively selected between January 2013 and June 2013, and the follow-up data were obtained between July 2013 and December 2013. For the evaluation of salt excretion levels in the control group, the average values obtained between January 2013 and June 2013 were used as the baseline values and those obtained between July 2013 and December 2013 were used as the follow-up values.

Hypertension was defined as a systolic blood pressure $\geq 140 \mathrm{mmHg}$, diastolic blood pressure $\geq 90 \mathrm{mmHg}$ or treatment with antihypertensive medications. Changes in blood pressure were evaluated in patients in whom antihypertensive medications were unchanged during follow-up. Congestive heart failure was defined as having symptoms of class II or above according to the New York Heart Association (NYHA) classification and/or congestive signs requiring loop diuretics at the time of entry. Diabetes mellitus was defined as fasting plasma glucose $\geq 126 \mathrm{mg} / \mathrm{dl}$, casual glucose level $\geq 200 \mathrm{mg} / \mathrm{dl}$, glycated hemoglobin levels $\geq 6.5 \%$, receiving oral hypoglycemic medications or using insulin.

The study protocol was approved by the ethics committee of Ueki Hospital, and informed written consent was obtained from all patients.

Estimation of salt excretion. Daily salt excretion levels were estimated using the following equation $(5,6)$ : Estimated 24-h urinary salt excretion $(\mathrm{g} /$ day $)=1.285 \times[\mathrm{Na}(\mathrm{mEq} / \mathrm{l}) / \mathrm{Cr}(\mathrm{mg} / \mathrm{l})$ in spot urine $\mathrm{x}$ expected $24 \mathrm{~h} \mathrm{Cr}$ excretion $]^{0.392}$, where the expected $24-\mathrm{h} \mathrm{Cr}$ excretion $(\mathrm{mg} /$ day $)=-2.04 \mathrm{x}$ age (years) $+14.89 \mathrm{x}$ weight $(\mathrm{kg})+16.14 \mathrm{x}$ height $(\mathrm{cm})-2244.45$.

Statistical analysis. Data are presented as the means \pm standard deviation. The event frequencies were compared using the $\chi^{2}$ test. Differences in the variables were compared using one-way analysis of variance when there were 3 groups, followed by Tukey-Kramer honest significant difference tests. Comparisons between the two groups of data were made using paired or unpaired Student's t-tests. A P level of $<0.05$ was considered to be statistically significant. The statistical software package JMP (version 9; SAS Institute, Cary, NC, USA) was used for the analyses.

\section{Results}

Characteristics of the patients. A total of 72 patients were included in this study. The baseline characteristics of the patients are presented in Table I; these characteristics were similar to those reported in previous studies $(3,4)$, with the exception that the salt excretion levels were considerably higher. There were no differences in the characteristics between patients who received dietary counseling and those who did not (the control group).
Changes in daily salt excretion. Fig. 1 shows the dietary salt excretion levels at baseline, 3-9 weeks and 24-52 weeks. The baseline estimated level of salt excretion was $11.3 \pm 1.5$ (range, 8.6-16.4) g/day, which was reduced to 9.6 \pm 2.3 (range, 4.6-14.4) g/day at 3-9 weeks, but increased again at 24-52 weeks to $10.4 \pm 2.1$ (range, 6.4-17.2) $\mathrm{g} / \mathrm{day}$, which was less than the baseline value. Fig. 2 shows the changes in the level of salt excretion from the baseline value. At 3-9 weeks, the change in salt excretion was $-1.7 \pm 2.5$ (range, -8.0 to 1.3 ) $\mathrm{g} / \mathrm{day}$, but at 24-52 weeks the change was reduced to $-0.69 \pm 3.0$ (range, -6.8 to 6.4 ) g/day, which was not different from that of age- and gender- matched control patients without dietary counseling $(-0.76 \pm 1.5 \mathrm{~g} / \mathrm{day}$; range, -5.4 to $3.0 \mathrm{~g} /$ day $)$. The number of patients in whom the reduction in salt excretion was $>2 \mathrm{~g}$ /day from baseline was 29 (40\%) at 3-9 weeks. Of these 29 patients, salt excretion was reduced by $<2 \mathrm{~g} /$ day or increased from baseline at 24-52 weeks in 14 patients. However, of the 43 patients in whom the reduction in salt excretion was $<2 \mathrm{~g} /$ day at 3-9 weeks, a reduction of $>2$ g/day was newly achieved in 7 patients; thus a reduction in salt excretion of $>2 \mathrm{~g}$ /day was achieved in $22(31 \%)$ patients at 24-52 weeks during follow-up evaluation. The numbers of patients who achieved salt excretion levels of $<6.0$ and $<8.0 \mathrm{~g} /$ day were only $4(5.6 \%)$ and 19 (26\%) at 3-9 weeks, respectively, and were further reduced to no patients $(0 \%$; $\mathrm{P}=0.043$ vs. $3-9$ weeks) and $9(13 \% ; \mathrm{P}=0.035$ vs. 3-9 weeks) patients at 24-52 weeks follow-up, respectively.

Effect of the number of measurements prior to dietary counseling on salt excretion. Fig. 3 shows the effect of the number of measurements made prior to dietary counseling on the levels of salt excretion. Salt excretion was measured $8.7 \pm 6.1$ (range, 1-24; median, 8) times prior to dietary counseling. Thus, the patients were divided into two groups according to the median number of measurements. Salt excretion was measured 4.0 \pm 2.6 (range, 1-8; median, 3.5) times in group $\mathrm{S}(\mathrm{n}=38)$, and 14.1 \pm 4.1 (range, 9-24; median, 13) times in group $\mathrm{L}(\mathrm{n}=34)$. The baseline level of salt excretion was not different between these two groups (11.2 \pm 1.4 vs. $11.4 \pm 1.7 \mathrm{~g} /$ day, respectively; $\mathrm{P}=0.44)$. Changes in salt excretion following dietary counseling at 3-9 weeks were also not different between these groups $(-2.0 \pm 2.6$ vs. $-1.4 \pm 1.8 \mathrm{~g} /$ day respectively; $\mathrm{P}=0.26)$. However, while salt excretion remained different from the baseline value at 24-52 weeks in patients in group $\mathrm{S}(\mathrm{P}=0.022)$, the difference disappeared in patients in group $\mathrm{L}(\mathrm{P}=0.50)$.

Effects on blood pressure. Of the 57 hypertensive patients included in this study, hypertensive medications remained unchanged in 34 patients. The systolic blood pressure was numerically reduced from $129.2 \pm 10.3$ to $125.2 \pm 11.7 \mathrm{mmHg}$; however, the difference did not reach statistical significance $(\mathrm{P}=0.066$, by paired t-test). The diastolic pressure was also not significantly changed from $75.1 \pm 8.0$ to $72.7 \pm 10.2 \mathrm{mmHg}$ $(\mathrm{P}=0.13$, by paired $\mathrm{t}$-test $)$.

\section{Discussion}

This study demonstrated that the efficacy of single-session dietary counseling by expert dieticians in reducing the salt intake of cardiology outpatients who consumed large amounts of salt was modest and only temporary, and achieving salt 
Table I. Characteristics of the patients.

\begin{tabular}{lccc}
\hline Characteristics & Case (dietary counseling) & Control & P-value \\
\hline Number & 72 & 72 & $30 / 42$ \\
Gender, female/male & $30 / 42$ & $73 \pm 10(46-92)$ & $25 \pm 3.7(15-34)$ \\
Age, years & $73 \pm 11(40-94)$ & $11.2 \pm 1.4(8.7-14.8)$ \\
Body mass index, $\mathrm{kg} / \mathrm{m}^{2}$ & $25 \pm 3.3(17-37)$ & $60(83)$ & 0.90 \\
Salt excretion, g/day & $11.3 \pm 1.5(8.6-16.4)$ & $21(29)$ & 0.82 \\
Hypertension, $\mathrm{n}(\%)$ & $57(79)$ & $10(14)$ & $11(15)$ \\
Diabetes mellitus, $\mathrm{n}(\%)$ & $16(22)$ & & 0.41 \\
Congestive heart failure, $\mathrm{n}(\%)$ & $16(22)$ & $46(64)$ & 0.34 \\
Permanent atrial fibrillation, $\mathrm{n}(\%)$ & $15(21)$ & $37(51)$ & 0.19 \\
Medications, $\mathrm{n}(\%)$ & & $17(24)$ & 0.39 \\
ACEI/ARBs & $41(57)$ & $11(15)$ & 0.094 \\
Calcium channel blockers & $27(38)$ & $4(5.6)$ & 0.14 \\
$\beta$-blockers & $25(35)$ & $13(18)$ & 0.65 \\
Loop diuretics & $10(14)$ & 092
\end{tabular}

Values are mean \pm standard deviation with the range in parentheses, unless otherwise indicated. ACEI, angiotensin converting enzyme inhibitor; ARB, angiotensin II receptor blocker.

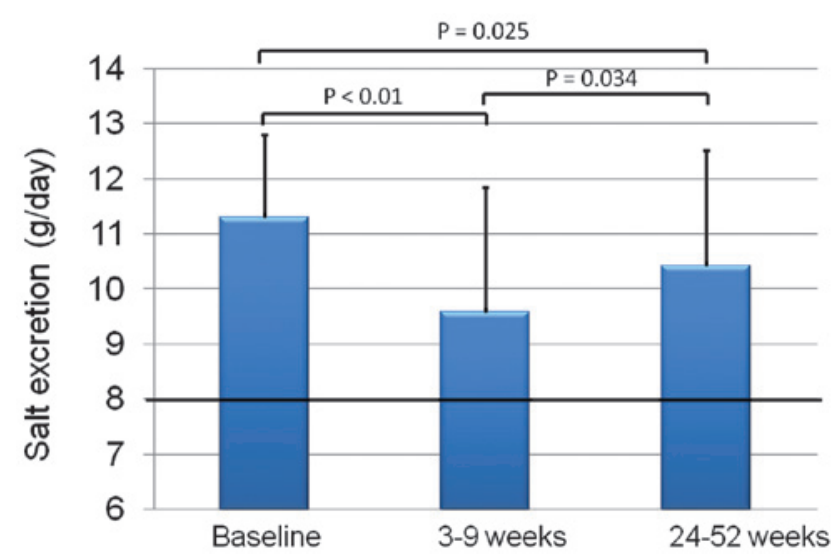

Figure 1. Dietary salt excretion at baseline, 3-9 weeks, and 24-52 weeks.

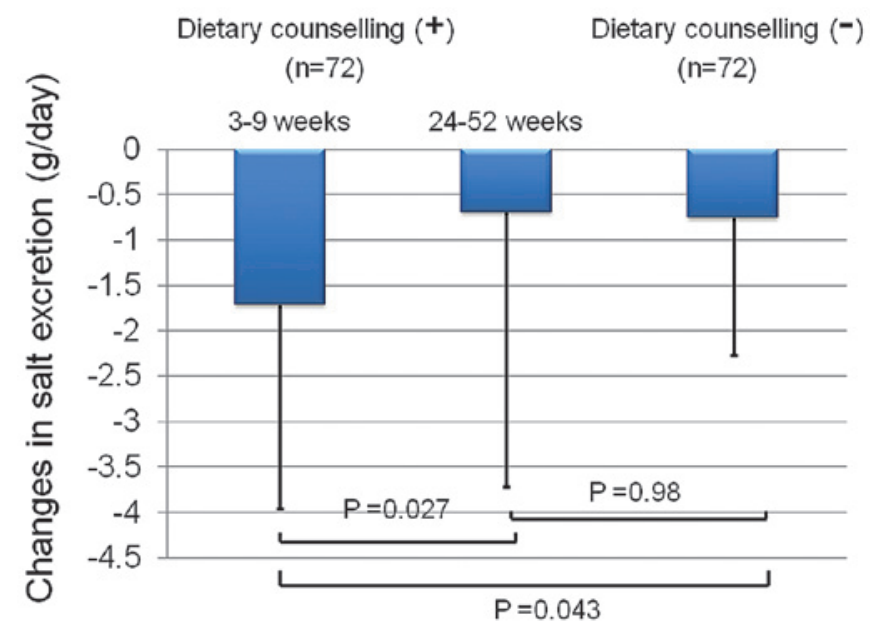

Figure 2. Changes in salt excretion from the baseline value.

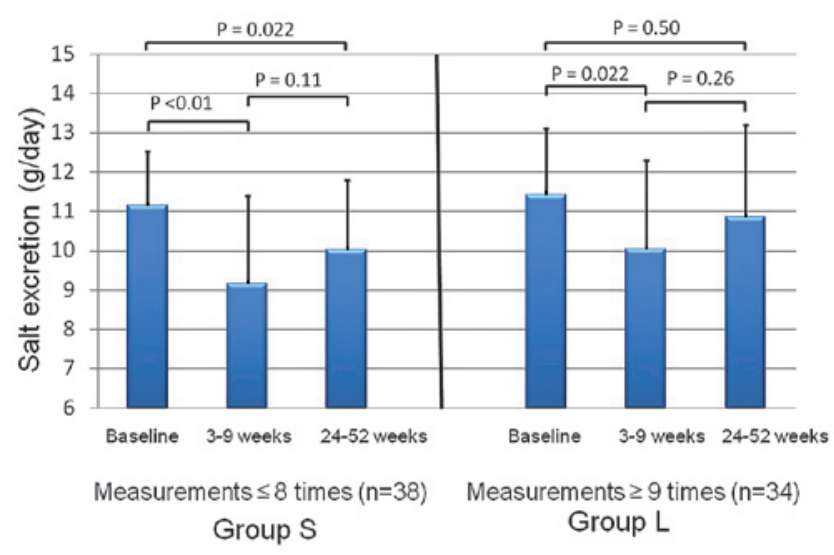

Figure 3. Effect of the number of measurements made prior to dietary counseling on salt excretion.

reductions to the level recommended by the guideline $(7,8)$ was very difficult in Japanese outpatients.

Previously, Buccicone et al (9) reported that single short (15 min) counseling sessions with advice on salt reduction by dieticians reduced the sodium intake estimated from the patients' recall of food eaten over the previous $24 \mathrm{~h}$ from $115.5 \pm 48.1$ to $51.7 \pm 33.9 \mathrm{mEq} / 24 \mathrm{~h}(\mathrm{p}<0.01)$. However, no effects were actually observed when using sodium excretion calculated from a 24 -h urine sample $(155.4 \pm 99.8$ to $137.4 \pm 52.8 \mathrm{mEq} / 24 \mathrm{~h}$; not significant). Similarly, Korhonen et al (10) reported that the 2-year net changes in daily sodium excretion were not different between a group that received intensified diet counseling (every 3 months) and a control group. The findings of the present study are consistent with these reports. However, more vigorous intervention, including 
group meetings and a free supply of low-salt bread, did reduce salt excretion $(11,12)$. Although single-session dietary counseling by dieticians in addition to simple counseling by attending physicians may seem to be unproductive efforts, particularly in patients who consume large amounts of salt despite repeated instructions by their attending physicians (Fig. 3), it was at least temporarily effective in some patients. Thus, it should always be considered possible to achieve reductions in salt intake in individual resistant patients. More comprehensive approaches, such as repeated dietary counseling in every office visit with multiple medical staff, including physicians, nurses as well as expert dieticians; group meetings or cooking sessions among similar patients who have not been able to reduce salt intake; and a short-term provision of low salt-containing food, for example, low salt soy sauce and low salt miso (fermented soybean paste) in the case of Japan, may be a feasible next step for further salt reduction in primary care settings (13).

The present study has certain limitations. First, the estimation of daily urinary salt excretion using a spot urine sample may be less accurate than that using 24-h urine collection, as previously noted $(3,4)$. However, it is difficult to collect 24-h urine in real-world practice. Second, this was not a randomized study and the patients were enrolled solely at the discretion of the attending physicians. Furthermore, control patients were retrospectively included. However, the control patients were well matched with the case patients for age, gender, body mass index and daily salt excretion (Table I), and the changes in salt excretion were consistent with those previously reported $(3,4)$. Thus, it is considered that selection bias was not sufficiently large to affect the main conclusions of the study. Third, dietary counseling by expert dieticians was performed only once according to the study design, and repeated counseling might have produced better outcomes. Fourth, the antihypertensive medications were changed in more than half of the patients who were included in this study during follow-up; thus, an evaluation of the changes in blood pressure observed in the present study is of limited value. Finally, this was a single-center study with a small number of patients; additional multicenter studies including a large number of patients are required.

In conclusion, the efficacy of salt restriction by dietary counseling by expert dieticians in patients who consumed large amounts of salt was modest and temporary. Multiple nutritional- and behavioral-oriented approaches should be considered for further salt reduction.

\section{References}

1. Appel LJ, Frohlich ED, Hall JE, Pearson TA, Sacco RL, Seals DR, Sacks FM, Smith SC Jr, Vafiadis DK and Van Horn LV: The importance of population-wide sodium reduction as a means to prevent cardiovascular disease and stroke. A call to action from the American Heart Association. Circulation 123: 1138-1143, 2011.

2. He FJ and MacGregor GA: A comprehensive review on salt and health and current experience of worldwide salt reduction programmes. J Hum Hypertens 23: 363-384, 2009.

3. Hirota S, Sadanaga T, Mitamura H and Fukuda K: Spot urine-guided salt reduction is effective in Japanese cardiology outpatients. Hypertens Res 35: 1069-1071, 2012.

4. Hirota S, Sadanaga T, Mitamura H and Fukuda K: Long-term compliance with salt restriction assessed using the spot urine method in Japanese cardiology outpatients. Hypertens Res 36: 1096-1099, 2013.

5. Matsuo S, Imai E, Horio M, Yasuda Y, Tomita K, Nitta K, Yamagata K, Tomino Y, Yokoyama $\mathrm{H}$ and Hishida A; Collaborators developing the Japanese equation for estimated GFR: Revised equations for estimated GFR from serum creatinine in Japan. Am J Kidney Dis 53: 982-992, 2009.

6. Tanaka T, Okamura T, Miura K, Kadowaki T, Ueshima H, Nakagawa $\mathrm{H}$ and Hashimoto T: A simple method to estimate populational 24-h urinary sodium and potassium excretion using a casual urine specimen. J Hum Hypertens 16: 97-103, 2002.

7. Kawano Y, Tsuchihashi T, Matsuura H, Ando K, Fujita T and Ueshima H; Working Group for Dietary Salt Reduction of the Japanese Society of Hypertension: Report of the Working Group for Dietary Salt Reduction of the Japanese Society of Hypertension: (2) Assessment of salt intake in the management of hypertension. Hypertens Res 30: 887-893, 2007.

8. Ogihara T, Kikuchi K, Matsuoka H, Fujita T, Higaki J,Horiuchi M, Imai Y, Imaizumi $\mathrm{T}$, Ito $\mathrm{S}$, Iwao $\mathrm{H}$, Kario $\mathrm{K}$, Kawano $\mathrm{Y}$, Kim-Mitsuyama S, Kimura G, Matsubara H, Matsuura H, Naruse M, Saito I, Shimada K. Shimamoto K, Suzuki H, Takishita S, Tanahashi N, Tsuchihashi T, Uchiyama M, Ueda S, Ueshima H, Umemura S, Ishimitsu T and Rakugi H; Japanese Society of Hypertension Committee: The Japanese Society of Hypertension Guidelines for the Management of Hypertension (JSH 2009). Hypertens Res 32: 3-107, 2009.

9. Buccicone $\mathrm{J}$ and McAllister RG Jr: Failure of single-session dietary counseling to reduce salt intake in hypertensive patients. South Med J 70: 1436-1438, 1977.

10. Korhonen M, Kastarinen M, Uusitupa M, Puska P and Nissinen A: The effect of intensified diet counseling on the diet of hypertensive subjects in primary health care: A 2-year open randomized controlled trial of lifestyle intervention against hypertension in eastern Finland. Prev Med 36: 8-16, 2003.

11. Korhonen MH, Litmanen H, Rauramaa R, Väisänen SB, Niskanen L and Uusitupa M: Adherence to the salt restriction diet among people with mildly elevated blood pressure. Eur J Clin Nutr 53: 880-885, 1999.

12. Elmer PJ, Grimm RH Jr, Flack J and Laing B: Dietary sodium reduction for hypertension prevention and treatment. Hypertension 17 (Suppl 1): I182-I189, 1991.

13. Ruzicka M, Hiremath S, Steiner S, Helis E, Szczotka A, Baker P and Fodor G: What is the feasibility of implementing effective sodium reduction strategies to treat hypertension in primary care settings? A systematic review. J Hypertens 32: 1388-1394, 2014. 